\title{
Fundamentos do institucionalismo na teoria social de Thorstein Veblen
}

\author{
Vagner Luís da Silva*
}

\section{Resumo}

O texto procura destacar os termos centrais presentes na obra do economista-sociólogo norte-americano Thorstein Veblen (1857-1929), apontando o alcance e os limites explicativos de tais conceitos. Termos como instinto, hábitos de vida e de pensamento, que corroboram a sua argumentação e procuram delinear de modo mais adequado seu esforço teórico, na tentativa de construir um modelo de análise para compreender a dinâmica social e econômica da $2^{\text {a }}$ Revolução Industrial, bem como contrapor-se à economia neoclássica de seu tempo. $\mathrm{O}$ resultado geral de sua obra realça a multidisciplinaridade típica das ciências sociais, fundamentando a abordagem que ficaria conhecida como institucionalismo vebleniano.

Palavras-chave: institucionalismo, instinto, hábitos, instituição.

\section{Introdução}

$\mathrm{O}$

objetivo aqui é discutir algumas formulações conceituais presentes na obra do economista-sociólogo norte-americano Thorstein Veblen (1857-1929), com a intenção de demonstrar o caminho percorrido pelo autor na elaboração das ideias que emergem de sua obra, inaugurando a heterogênea corrente institucionalista nas ciências sociais e definindo, de modo mais acabado, a particular perspectiva evolucionária na economia de seu tempo ${ }^{1}$.

* Doutor em Sociologia (Universidade de São Paulo). Professor do Instituto Federal São Paulo (IFSP - São João da Boa Vista - SP). Endereço eletrônico: vagnerls@usp.br.

1 Como já apontamos em trabalho anterior, Veblen não cunhou a expressão "institucionalismo" em alusão a sua teoria, apesar de usar abundantemente 
A rigor deve-se esclarecer que a definição do institucionalismo não é propriamente muito clara no conjunto das ciências sociais. Não se pode afirmar que tal corrente de interpretação constitua uma escola no sentido estrito do termo, como costumeiramente se faz com relação ao marxismo ou ao funcionalismo, por exemplo. Muito do que se convencionou chamar de estudos institucionais estava, na verdade, vinculado a outras matrizes de pensamento, quando não aos clássicos das ciências sociais, como Marx ou Durkheim. Assim, não é incomum encontrarmos correntes interpretativas que são ligadas ao institucionalismo - com ou sem a anuência delas - nas mais diversas áreas das ciências sociais, como sociologia, ciência política ou economia. O debate não se definiu ainda, haja vista o renovado fôlego, a partir dos anos 70 e 80 , do que ficou conhecido como neo-institucionalismo.

Porém, a despeito da polêmica em torno da validade ou da importância dos estudos institucionais como componentes da análise social, é inequívoca a lembrança de Veblen entre os fundadores dessa linha de investigação. Quer nas ciências sociais em sua totalidade ou estritamente na sociologia ou na economia, o autor sempre frequenta o rol dos expoentes no estudo das instituições. O peso de seus trabalhos foi sentido, de modo central ou periférico, no ambiente acadêmico norte-americano ao longo de todo o período anterior à Segunda Guerra Mundial (BLAUG, 1999, p.124; ROSS, 1997, p.172).

Importa-nos, aqui, esclarecer algumas definições dadas por Veblen para instintos, hábitos de pensamento e instituições, bem como a relação desses temas com o que na história da análise social denominou-se de institucionalismo vebleniano. Numa análise mais aproximada, o que se procura é avaliar o desenvolvimento de sua teoria e seu livre trânsito da economia para a sociologia, colhendo pistas que permitam evidenciar, através de alguns de seus conceitos, o caminho apontado por Veblen para a economia norte-americana

termos como instituições, mudança institucional, institucionalização, entre outros (SILVA, 2008, p.135-36). Lallement (2006) indica que "institucionalismo" vincula-se à tradição historicista norte-americana de fins do século XIX, consagrando-se, porém, mais tarde, quando da aprovação do estatuto da American Economic Association, em 1918. 
de então: o abandono da compreensão individualista metodológica como meio de explicação dos fenômenos sociais, com a devida influência da tradição neoclássica de sua época, para assumir uma ótica muito próxima do holismo metodológico.

\section{Instinto}

Ordinariamente as ciências da natureza tratam do instinto como resposta automática dos seres vivos, sob determinadas condições, às demandas do meio e àquelas provocadas por outros seres vivos. Contudo, a definição biológica de instinto não está muito próxima daquela pretendida por Veblen. No seu terceiro livro, The Instinct of Workmanship and the State of Industrial Arts, publicado em 1914 e considerado o mais eloqüiente para o tema institucionalismo, Veblen dá ao instinto uma centralidade essencial para o entendimento de sua argumentação. De imediato sustenta que a natureza humana é conduzida por "disposições instintivas" e através delas o homem molda a sua ação em grupos. $O$ autor sugere que os instintos que permeiam o homem aparecem como "propensões inatas" e de seu funcionamento "brotam não só o propósito e a eficiência da vida, mas também seus prazeres substanciais e sofrimentos" (VEBLEN, 1989, p. 1). O encaminhamento do tema resvala na definição biológica do instinto, mas a ela não se limita. $O$ instinto como componente da natureza humana só é completo, na opinião de Veblen, se agregarmos a ele um outro elemento indispensável: a teleologia.

As expectativas que envolvem a ação humana voltam-se para um sentido pragmático em vista das possibilidades de ganhos ou de maximização de resultados em meio ao ambiente social. Segundo Veblen, é neste quadro que se define o comportamento teleológico na ação dos indivíduos.

Ação instintiva é teleológica, consciente então, e o alcance teleológico e visado de cada propensão instintiva difere caracteristicamente de todo o resto. Os vários instintos são categorias teleológicas, e são, num uso coloquial, distinguidos e classificados sobre o terreno de seu conteúdo teleológico. (...) 'Instinto', contrariamente à ação tropismática, envolve consciência e adaptação para um fim visado" (1989, p. 3-4). 
Assim, não se pode identificar a ação instintiva nos limites subordinados ao organismo. Na noção de instinto, sob a ótica vebleniana, o entendimento da dinâmica dos sistemas sociais só é possível na medida em que incorporamos novos elementos de interpretação. Esses novos elementos funcionam como recursos auxiliares na avaliação do peso da inteligência humana em convergência com fatores biológicos, cujo objetivo maior é maximizar os interesses particulares ou coletivos em vista de um meio social. Isto é, na análise da noção de instinto em Veblen, a inteligência humana aparece como componente privilegiado na compensação dos fatores inconscientes - instintivos - em meio aos imperativos sociais.

De antemão é preciso discernir a ação social na forma como foi pensada por Veblen do que caracteristicamente se apresentava como darwinismo social. O pensamento vebleniano, ao pautar a ação social pela consciência e pelos fins visados, colocava-se em franca oposição ao modelo de ação compreendido somente nos limites da biologia ou dos fatores materiais a ela ligados. Por consequência, o autor em nada se associou aos seus contemporâneos que, sob o impacto de Herbert Spencer e das ideias darwinistas, compuseram doutrinas pautadas pela lógica da preservação do mais apto como princípio instintivo, sob o qual as ações humanas estavam inevitavelmente restritas.

De todo modo, fica evidente que o instinto, conforme apontamento de Veblen, não se coaduna com imperativos puramente intuitivos e inconscientes. A ação dos seres humanos, como seres gregários dotados de senso de comunidade, é produto de um complexo variado de fatores tão mais difíceis de discernir quanto maiores são as variantes que se impõem aos homens. Queremos dizer que se a ação é dotada de um sentido teleológico, emoldurada pela inteligência e pela definição de determinados objetivos, também dela participa aquilo que está inconsciente ou fora do alcance da racionalidade imediata. Curioso destacar que a opção do teórico diz respeito à razão, mas permite incorporar o que é inconsciente na explicação da interação social, daí o seu entendimento de instinto diferir da explicação tradicional, restrita à biologia, mobilizando, ao mesmo tempo, a racionalidade e a capacidade de escolha dos indivíduos. Assim, o autor não dialoga com uma noção restritiva tanto para o entendimento do instinto quanto da ação social. 
Isso esclarece o propósito do autor de guarnecer a ação instintiva com imperativos herdados socialmente. Isto é, não se tem nem sociedade e nem ação social sem história, haja vista que esta fornece o balizamento necessário para os simbolismos, os padrões de conduta ou valores, as regras e demais fatores imateriais que contribuem para a disposição dos atores e sua natural interrelação. Esse conjunto de elementos é chamado por Veblen de "hábitos de pensamento", que são necessariamente acumulados "através da experiência de gerações passadas” (1989, p. 7). Pode-se, desse modo, resumir o desempenho do homem em sociedade pela confluência da motivação biológica, do suporte sócio-histórico e da racionalidade. Para Veblen, tem-se os fatores ligados à reprodução, à sobrevivência, à sexualidade, entre outros, num primeiro momento, devidamente arranjados conforme pressupostos sociais definidos historicamente, em conjunção com o primado da razão, decidindo por aquilo que maximiza interesses imediatos.

A questão central é concluir qual dos fatores tem primazia sobre os demais. De outro modo, para Veblen, trata-se de estabelecer qual deles funciona como causa necessária para a orientação da ação social. Entretanto, do ponto de vista vebleniano, não há como definir automaticamente a relação causal no jogo da interação social. A inteligência, de imediato, ganha um status central na compensação dos objetivos a serem conquistados. Contudo, que não se deprecie o poder das forças inconscientes, dado o seu caráter periférico, pois, conforme o autor, tais forças podem imputar um direcionamento mais relevante do que aqueles conscientes.

Como a expressão é aqui compreendida, toda ação instintiva é inteligente em algum grau; apesar de o grau no qual a inteligência está comprometida poder variar amplamente de uma disposição instintiva para outra, e ela pode partir de uma forma extremamente automática no caso de alguns simples instintos, para os quais o conteúdo funcional é de um caráter patentemente fisiológico" (VEBLEN, 1989, p. 30).

Logo, temos em Veblen que os pré-requisitos da ação supõem graus variados de capacidade cognitiva a definir fins e delimitar estratégias de ação. Ou seja, explicita-se a noção de que do instinto participa a inteligência, mas também incorpora os imperativos 
definidos pelo costume ou pelo que é dado por forças fisiológicas. Até por isso o autor atribui aos instintos "traços hereditários", não reduzindo a expressão ao universo da biologia, mas ampliando-a com componentes sócio-históricos (1989, p. 13).

Entretanto, como "toda ação instintiva é teleológica" (1989, p. 31), ponderamos que a inteligência está mais presente nas interações que requerem maior acuidade na definição dos objetivos. Nesse sentido, parece que a razão, na teoria vebleniana, serve mais como um farol que foca de imediato aquilo que nos atrai o interesse, deixando os demais eventos num plano secundário sob a tutela de relações causais coadjuvantes, ao sabor de forças exógenas dadas socialmente e por conta das necessidades biológicas. Simultaneamente, da razão não se ausentam tais forças como fatores condicionantes automáticos. De outro modo, parece razoável compreender que, na perspectiva do autor, a relevância dos fins visados serve para estabelecer ou não o grau de participação da razão nas disposições instintivas. Nas ações sociais em que a inteligência está na periferia, ressalte-se o peso do "caráter fisiológico" como força motriz, reino da intuição e das motivações inconscientes.

A disposição instintiva, para Veblen, quando mobilizada num nível puramente fisiológico, é capaz de conformar uma gama de atitudes e padrões que servem de referência ou de motivação para um dado grupo social. Neste ponto, a noção vebleniana de instinto abranda os seus vínculos com a racionalidade para se aproximar das determinações apresentadas pelas normas sociais. Note-se, contudo, que, para o autor, o exercício das disposições instintivas nunca dissipa a racionalidade por inteiro. Outrossim, as normas sociais seriam formadas inicialmente pelo jogo natural das relações sociais na busca da sobrevivência.

Os modos costumeiros de fazer e pensar não somente tornam-se uma matéria habitual, fácil e óbvia, mas chegam igualmente a ser sancionados pela convenção social, e então se tornam corretos e apropriados, originando princípios de conduta (VEBLEN, 1989, p. 7).

O instinto vebleniano resulta na conformação de instituições sociais, reguladoras, por natureza, da ação social. A história da humanidade poderia ser registrada pela renovação incessante dessas 
instituições, motivada em certa medida pelas disposições instintivas. Nesse sentido, o teórico sugere a existência de instintos universais, como o da produção e o predatório ou, ainda, o da curiosidade ociosa e o paternal, que estariam presentes em toda a humanidade desde remotos tempos.

$O$ instinto paternal e o da curiosidade ociosa apresentam-se de modo mais periférico no conjunto dos textos do autor. Ao primeiro poderia se ligar o instinto humano da autopreservação. Ele está voltado para a proteção dos filhos e demais descendentes. A reprodução, a manutenção e a previdência são seus atributos básicos, cujo fim é a preservação dos "interesses comuns do grupo e a tutela das gerações vindouras” (VEBLEN, 1989, p.44). Acerca do instinto da curiosidade ociosa, Veblen propõe a existência de uma motivação humana que empurra o homem para o conhecimento de si mesmo e do meio em que vive. Não seria necessariamente um conhecimento aplicável ou prático, tampouco um conhecimento estritamente científico, mas uma propensão inata que, juntamente com o instinto de produção, separa o que é próprio da "natureza humana da propensão instintiva refratária dos baixos animais” (VEBLEN, 1989, p.86).

Os instintos da produção e o predatório compõem um eixo de referência na compreensão da teoria vebleniana. Entendê-los significa compreender o ponto de partida e os desdobramentos do pensamento de Veblen. Tais instintos figuram em pólos opostos e em conflito permanente. A eles se associa o comportamento humano ao longo da história, quer como agente da dinâmica da realização, do empreendimento, da conquista ou da organização ou como instrumento da destruição, da exploração ou do atraso. O instinto da produção existe desde o desenvolvimento das sociedades humanas na pré-história, num estágio de selvageria pacífica, momento em que se estreitavam os laços sociais dos pequenos grupos com vistas à sobrevivência da espécie (VEBLEN, 1989, p.32-37; 1965a: p.29-35). Desde a sua formação, tal instinto ocupa-se, basicamente, de "expedientes práticos, caminhos e meios, invenções e instrumentos de eficiência e economia, habilidades, trabalho criativo e tecnologia" (1989, p.33). Está voltado para a cooperação, a técnica, as artes e as ciências e a ele se atribui uma inclinação para o melhoramento das condições de vida da humanidade. $\mathrm{O}$ instinto da produção adquire 
relevo na teoria vebleniana na medida em que dele participam os empreendedores ao longo da história.

A visão desse instinto está sombreada pela concepção evolucionista de Darwin, pois Veblen parte do princípio de que tal instinto é condição para a adaptação e o progresso do grupo social. Assim, o instinto da produção alterna-se com o instinto predatório na definição do comportamento humano, quer individual ou coletivo, numa relação dicotômica e necessária que se desdobra na formação e desenvolvimento das instituições sociais.

Ao instinto predatório cabe o papel de fomentador do conflito dentro dos grupos sociais. Para tanto, teria se originado na transição da fase da selvageria pacífica para a fase definida por Veblen de predatória (1965a, p.32). São seus aspectos constitutivos: a agressividade, a competição dos indivíduos pelas posições hierárquicas vantajosas, a guerra entre grupos, a formação de segmentos sociais com poder de exploração, o domínio de natureza sexual ou econômico e demais práticas que demandam o poder de mando e a capacidade de coerção. Veblen supõe que o instinto predatório seja consequência da institucionalização de práticas provenientes do instinto da produção. Uma vez garantidas as condições de sobrevivência da espécie, devidamente arraigadas pelo instinto da produção, os homens passariam gradualmente da cooperação à competição. Ou seja, o instinto predatório estimularia a rivalidade e a busca de vantagens sociais entre os indivíduos de um dado grupo social.

Ao longo do processo histórico, tal instinto acarretou a formação de instituições que teriam por finalidade acobertar a natureza da exploração social (VEBLEN, 1965a, p.32). É o caso do esporte, das formalidades sociais refinadas, do status, ou ainda da caça, do galanteio, e demais atributos permeados muitas vezes de suposta honraria ${ }^{2}$. De início, porém, o instinto predatório possibilitou o surgimento de uma classe ociosa devidamente cingida pela

2 Este tema foi tratado com particular atenção por Veblen em A Teoria da Classe Ociosa. Utilizando-se da sua regular crítica ácida, porém precisa, o autor recheou a sua obra de exemplos não só da capacidade predatória do homem, mas de sua aptidão para dissimular a predação por meio de subterfúgios sociais de ampla aceitação. 
distinção e pela honra. Duas, pelo menos, são as condições para o afloramento dessa classe, conforme Veblen:

“(1) a comunidade deve ter um modo de vida predatório (...); os homens, que nestes casos constituem a classe ociosa em potencial, devem estar habituados a infligir dano físico pela força ou por estratagema; (2) a subsistência deve ser possível de modo suficientemente fácil para que uma parte considerável da comunidade fique livre da rotina regular do trabalho" (1965a, p. 24).

Desse modo, a classe ociosa nasce sob o signo da diferença, marcada pela separação de funções na sociedade. De um lado, os indivíduos envolvidos pela dignidade, conferida pela "proeza ou façanha”, de outro, os demais membros do grupo rebaixados pela indignidade de suas funções sociais, resultado de práticas "diárias e rotineiras em que nenhum elemento espetacular existe” (1965a, p. 25).

O natural desenvolvimento do instinto predatório ocasionou no capitalista moderno, paradoxalmente, um comportamento pecuniário e desinteressado da produção de bens sociais. $O$ papel que the cabe não é aquele interessado na maximização de resultados, ao contrário, antes sobre ele recai o papel de sabotador do sistema produtivo. O empreendimento, na forma como Veblen o via, volta-se para as condições de exploração do sistema produtivo e mais ainda para os mecanismos de apropriação financeira, de composição de trustes e cartéis (1932: p. 185-89). O mercado de capitais e o acúmulo de ativos imateriais ganham importância crescente na atividade pecuniária, tanto quanto as crises econômicas que redundam em destruição dos competidores e agregam valor ao capital pecuniário vitorioso. Não por outra razão, Veblen atribuiu aos corretores e banqueiros modernos, financistas e burocratas a responsabilidade pela desorganização de interesses positivos, oriundos da tendência cooperativa motivada pelo instinto da produção. Seriam os mais afeitos a destilar o instinto predatório, envolvidos pela competição destruidora, pelo ócio e pelo consumo conspícuo, na expressão vebleniana.

\section{Hábitos}

Como consequência do conceito vebleniano de instinto ou de disposição instintiva, origina-se o de hábitos. Em Veblen, o hábito 
aparece como solução para se transpor o caminho da disposição instintiva para a instituição. Na esteira das práticas e usos cotidianos na esfera da materialidade, o hábito é referenciado como hábito de vida; já como fenômeno imaterial dessas mesmas práticas, é definido, pelo autor, como hábito de pensamento. Assim, Veblen manifesta que os "hábitos de pensamento resultam dos hábitos de vida” (1969, p. 38). Isto é, atitudes pretéritas incorporadas de modo usual tornam-se referência para os membros de uma sociedade, de tal modo que os indivíduos refletem tais práticas como naturais, intemporais ou mesmo necessárias. A interrelação dos sujeitos emerge em meio à atmosfera criada pelas disposições habituais. Vimos nos parágrafos precedentes como a própria percepção do instinto em Veblen é aprumada pelos fatores imateriais que balizam a ação social. Tais fatores, definidos como hábitos de pensamento, corrigem, de certo modo, por meios sociais, as propensões instintivas de natureza inata.

De resto, hábitos e instintos parecem convergir para galvanizar a ação social do indivíduo com disposições frequentemente fora de sua capacidade de racionalização. O hábito, uma vez consagrado socialmente, cristaliza-se de modo quase inabalável. Mesmo que o indivíduo não faça ideia de sua origem ou de sua aplicabilidade, o hábito pode persistir sem que ninguém ou nada o altere. Dessa forma, o sujeito está subordinado a imperativos que, no mais das vezes, fogem ao seu controle.

Em outras palavras, e de modo geral, poder-se-á dizer que os hábitos mais antigos e arraigados que governam a vida do indivíduo - aqueles que afetam a sua existência como um organismo - são os mais persistentes e imperiosos. (...) Em geral, quanto mais antigo o hábito, tanto mais inquebrantável; e quanto mais um determinado hábito coincidir com os costumes, tanto maior a persistência com que se fixará (VEBLEN, 1965a, p.108).

Novamente se impõe o dilema da indefinição da vontade humana como condutora de desígnios racionais. À parte das necessidades de concluir os fins visados de modo individual e solitário, as disposições habituais tomam a dianteira para garantir que não se alienem os fins sociais. Em outras palavras, os hábitos que 
"governam a vida do indivíduo" fixam a ação social nos limites da aceitação do grupo. Logo, a operacionalização dos objetivos de caráter individual deve se processar nas veredas ou brechas abertas ou permitidas pelos próprios hábitos.

O hábito será mais firme se as tendências especiais da natureza humana que a sua prática abranger, ou as aptidões particulares que nele encontrem a sua expressão, forem tendências ou disposições já larga e profundamente envolvidas no processo vital, ou intimamente ligadas à história da vida de um determinado grupo racial (1965a, p. 108).

Não se encontra prática social que esteja fora do alcance das disposições habituais. Hábitos de vida de há muito tornados eficientes convertem-se em hábitos de pensamento. Uma vez perpetuados na história, diminuem a capacidade dos homens de promover mudanças efetivas nas organizações sociais ou políticas, bem como alterações significativas de padrões culturais dispostos desde longa época. Por isso Veblen admite que "leva tempo para que qualquer mudança impregne as massas e altere a atitude habitual das pessoas" (1965a, p. 105). Nestes termos, a concordar com os conceitos veblenianos de instinto e hábito, aceita-se um desdobramento histórico que está mais para a continuidade do que para a ruptura. Antes do que divergência, os processos sociais apresentamse dotados de uma harmonia imposta pelo amplo repertório das disposições habituais.

Nesse caso, há uma clara inclinação das teses veblenianas para conclusões muito próximas daquelas que apresentam os seres sociais como personagens levados de arrasto por motivações das quais pouco ou em nada participam. O universo da racionalidade efetiva, de menor relevância, pode abrigar interesses que, consoantes com a tradição habitual, voltam-se para a maximização de resultados calculados. De modo oposto, àqueles que se aventuram pelas práticas sociais não condizentes com a força da tradição, resta o perigo da marginalidade. Num trecho em que analisa o consumo conspícuo da classe ociosa, Veblen permite entrever o que considera como as etapas em que são estabelecidos os interesses e consequentes práticas individuais e coletivas: 
Primeiramente uma coisa é desejada por um motivo definido; mais tarde ela passa a ser desejada por si mesma, adquire nos nossos hábitos de pensamento o caráter de substancialmente desejável. No tocante às normas específicas de comportamento, todavia, uma norma determinada permanece em vigor somente quando tem o apoio do hábito ou aptidão que constitui o critério de seu desenvolvimento, ou pelo menos não é com ele incompatível (1965a, p. 69-70).

Veblen pondera que ainda que um fim estritamente racionalizado seja a raiz de um impulso social, não decorre daí que ele seja conquistado. A realização dos fins depende da naturalização dos mesmos como hábitos de pensamento. As normas aparecem aqui como corolário dos hábitos instituídos, tendo por direção as inclinações habituais. Nesse esquema, Veblen admite que sobre o instinto aplica-se a disposição habitual - hábitos de vida tornados hábitos de pensamento. Entendemos, aqui, o instinto nos limites em que recebe influência do meio, isto é, das normas sociais. Não por outra razão que o autor começa o capítulo II, de The Instinct of Workmanship and the State of Industrial Arts, afirmando que "todo comportamento instintivo está sujeito ao desenvolvimento e, portanto, à modificação pelo hábito" (VEBLEN, 1989, p.38).

Assim, o universo material ou do mundo prático tem relevância justificada na teoria vebleniana, haja vista que expressa os requisitos para o processo de habituação. Tal processo tem, em regra, um caráter geral, isto é, atinge todos os membros da comunidade. É dotado, ainda, de uma capacidade não desprezível de permanência, resultando em maior estabilidade para o conjunto social.

No homem o hábito toma um caráter acumulativo, essas aptidões habituais da raça são transmitidas de uma geração para a próxima, pela tradição, treinamento, educação, ou qualquer termo geral que pode melhor designar a disciplina de habituação pela qual o jovem adquire o que o velho tem para ensinar. (...) Cumulativamente, portanto, o hábito cria usos, costumes, convenções, preconcepções, compõe princípios de conduta que fluem somente de modo indireto para a predisposição nativa da raça (VEBLEN, 1989, p. 38-9).

É inequívoco que a compreensão de Veblen dos hábitos origine um singular sentido de cultura. Evidentemente as disposições 
habituais associam-se às normas de comportamento, às práticas e costumes cotidianos, aos valores e demais fatores que se vinculam à dinâmica cultural. A despeito da amplitude do conceito de cultura, na teoria vebleniana, o "esquema cultural de qualquer comunidade [apresenta-se como] um complexo de hábitos de vida e de pensamento prevalecente entre os membros dessa comunidade" (VEBLEN, 1969, p. 39). Assim, fixa-se definitivamente o sentido que o autor dá para as disposições habituais, contemplando um universo de práticas sociais e, simultaneamente, permeando-o de simbolismos admitidos pelo conjunto da sociedade.

Veblen trabalha o conceito de hábito para poder melhor explicar as condições em que determinadas práticas institucionalizam-se. O objetivo não é outro que não seja a definição, ao longo da história, de instituições que permitam a relação de poder e exploração entre os homens. $\mathrm{O}$ fenômeno da exploração apresenta-se devidamente alicerçado naquilo que o autor denomina de hábito predatório, fomentado pelo instinto de mesma natureza. Disso decorre a relação dicotômica que permeia a teoria vebleniana: "a atividade industrial se sobrepõe à atividade predatória na vida diária da comunidade e nos hábitos de pensamento dos homens" (VEBLEN, 1965a, p. 41). À primeira atividade associam-se os "operários, trabalhadores e técnicos”, cuja prática é movida por hábitos voltados para a construção e para o bem-estar social da comunidade (VEBLEN, 1989, p.188). À segunda associam-se os "proprietários, investidores, patrões, empregadores, homens de negócios”, cuja prática volta-se exclusivamente para a atividade pecuniária, mobilizados pelo hábito predatório (1989, p.189-90).

Num esforço de síntese podemos, resumidamente, pontuar da seguinte forma o encadeamento das concepções veblenianas de instinto e hábitos. Primeiro: o instinto é influenciado por (a) forças fisiológicas ou inconscientes, (b) normas sociais e (c) pela razão, dado seu caráter teleológico; quando apontada a influência de forças fisiológicas (a), o autor pretendeu dar ao instinto um caráter geral e próprio de todo ser humano; quando apontada a influência das normas (b), o autor pretendeu caracterizar o instinto em sua natureza social. Segundo: a natureza social das práticas cotidianas consolida hábitos de vida; tais hábitos, por sua vez, transformam-se 
em hábitos de pensamento, institucionalizando costumes que têm a prerrogativa de alimentar as normas sociais.

É preciso considerar, em princípio, que a ação em Veblen é dotada de alguma indefinição, esboçando-se nela os componentes socialmente aceitos mais os interesses individual ou coletivamente arquitetados. Não por outro motivo, o teórico fala em "sensibilidade tropismática”, como ato reflexo exclusivamente originado de estímulos psicológicos ou fisiológicos, quando pretende caracterizar uma ação humana involuntária e isenta de qualquer racionalidade (1989, p.9). Mas, em se tratando de instintos, o autor impregna sua natureza de atributos mais complexos, como discutimos anteriormente, numa mistura que ultrapassa o limite estreito do tropismo para alcançar a racionalidade e o condicionamento exógeno.

Sobre instintos e hábitos, na teoria vebleniana, vale ressaltar ainda um último ponto. A noção mais corrente que se depreende das posições de Veblen diz respeito a alguma indiferença quanto ao poder da racionalidade; algo dessa indiferença se articula na obra do autor como contraponto a um aspecto essencial da economia neoclássica: o princípio de um indivíduo racional capaz de controlar as variáveis sociais e maximizar seus interesses. A radical discordância do teórico frente aos neoclássicos talvez tenha contribuído para marcar ainda mais o seu distanciamento dos métodos individualistas, considerando que o autor imputava à capacidade cognitiva limites mais estreitos quanto ao seu poder na definição de fins e na opção por estratégias para a maximização de resultados imediatos. Como vimos anteriormente, a inteligência operaria sob condições dadas pelos hábitos de pensamento forjados desde o passado, mas teria uma capacidade instrumental de seguir um roteiro próprio, quando eventualmente pudesse se favorecer de brechas institucionais.

Nesse sentido, a posição vebleniana guarda alguma semelhança ou busca alguma inspiração na filosofia pragmática norteamericana, que lhe foi contemporânea. O conceito de hábito, a exemplo, poderia encontrar paralelo tanto em Willian James e John Dewey quanto em Charles S. Peirce. O primeiro, segundo Hodgson, aparece como um dos principais arquitetos da psicologia das propensões instintivas, responsável por uma ideia de hábito que implica na "adoção prévia de padrões de comportamento" ou em 
"comportamento não-reflexivo que se origina de situações repetitivas" (HODGSON, 1998, p.177-78). O segundo, na avaliação de Waller, utilizou-se do conceito de hábito de modo mais extensivo que todos os demais de sua época, apresentando-o como baliza para a atividade intelectual e como meio que se destina a fixar aspectos rotineiros dos comportamentos sociais (WALLER, 1993, p.12). Peirce, por sua vez, imputava ao "comportamento habitual" a orientação necessária das "circunstâncias familiares", sinalizando o papel dos hábitos na conservação de traços arcaicos socialmente absorvidos, o que acabou por influenciar fortemente a concepção vebleniana (WALLER, 1993, p.10-11).

Porém, em Veblen, sabemos que o hábito favorece-se da sua concepção de instinto, propensão inata que em sua manifestação é capaz de conjugar hábitos de pensamento com algum sentido teleológico e o atributo imperativo das forças condicionantes socialmente dadas. Não por outra razão, na teoria vebleniana, é a dimensão social do hábito, como norma cultural que se sobrepõe aos comportamentos sociais, que adquire relevância em detrimento da escolha racional individual, sendo tal ênfase a principal diferença que contrasta Veblen à concepção de Peirce, se quisermos concordar com a sugestão de Waller (1993, p.10-11).

\section{Instituições e dinâmica institucional}

Quando Veblen pensa na cristalização de sistemas de valores, de práticas cotidianas, de costumes, de visão de mundo e demais essencialidades que se vinculam às normas sociais, ele pensa no desenvolvimento de instituições. Não por acaso, o autor define instituições como hábitos de pensamento que são próprios de uma sociedade em sua época (VEBLEN, 1969, p.239). Como hábitos de pensamento resultam dos hábitos de vida, reforçando-os, podemos assim dizer que a instituição referencia-se por uma dupla dimensão: a do universo material, criando usos, e como fenômeno imaterial, na captação desses usos e na interpretação das práticas sociais. A instituição, portanto, remete ao caráter coletivo de experiências comuns de um grupo. Sobre ela recai o inequívoco papel de intensificar usos e costumes para promover a fluidez da 
dinâmica social. Isto é, a instituição serve para balizar a ação dos indivíduos em meio à coletividade.

Estabilidade e permanência são pressupostos da instituição, na forma como ela foi compreendida por Veblen, assim como sua vocação para dar homogeneidade ao grupo. As relações sociais confluem para o compartilhamento de simbolismos e toda a sorte de vicissitudes próprias que se realizam num nível compreensivo. Estão ausentes as alterações abruptas, superando-se, assim, as inquietações do grupo frente ao turbilhão de eventos da dimensão social. Por isso, estabilidade coaduna-se com permanência. Tal entendimento implica na aceitação da força da tradição.

As instituições - o que vale dizer, os hábitos mentais - sob a orientação das quais os homens vivem, são por assim dizer, herdadas de uma época anterior; época mais ou menos remota, mas, em qualquer caso, elaboradas no passado e dele herdadas. As instituições são o produto de processos passados, adaptados a circunstâncias passadas, e por conseguinte nunca estão de pleno acordo com as exigências do presente" (VEBLEN, 1965a, p. 179).

O delineamento da história de uma comunidade tem por referência toda a gama de valoração instituída, sem a qual não se realiza o jogo da interação social. As expectativas e soluções, que porventura brotam dos conflitos internos à coletividade, constituem apenas o resultado daquelas condições instituídas. A biografia de uma sociedade está inequivocamente amarrada ao conjunto institucional por ela produzida ao longo do tempo.

Pode-se dizer que a homogeneidade aparece como outra qualidade da instituição vebleniana. Nenhum agente de um determinado universo social está impermeabilizado frente às influências dos padrões de conduta ou simbolismos produzidos pela sociedade de sua época. Logo, a homogeneidade constitui a garantia de que a instituição terá uma abrangência geral, isto é, atingirá a todos os membros da coletividade com o mesmo peso e rigor, servindo para padronizar hábitos de pensamento.

Veblen pondera que as instituições têm uma "força prescritiva habitual”, reunindo os indivíduos na promoção da sociedade: "a estrutura institucional da sociedade subsiste e os homens vivem 
dentro de seus limites" (1964a, p.143). A arquitetura social não permite maiores desníveis na prática social: se cada um agisse por si e "não com base nos fundamentos e valores convencionais da trama das instituições [...] não haveria instituições nem cultura" (1964a: p. 143). A percepção da natureza permanente e totalizante da instituição pode ser averiguada na capacidade de comunhão dos hábitos de pensamento. Neste ponto interessa ressaltar um elemento substantivo dessa discussão: o poder coercitivo da instituição. Apesar de o autor não insistir na ideia de coerção, ela é um produto natural da equação envolvendo hábitos de vida, hábitos de pensamento e instituição. Relações sociais não se efetivam sem que a coerção esteja presente para emoldurar a ação social.

A situação de hoje modela as instituições de amanhã mediante um processo seletivo e coercitivo, atuando na habitual opinião humana sobre as coisas, e assim alterando, ou envigorando um ponto de vista ou uma atitude mental herdada do passado (VEBLEN, 1965a, p.179).

Por isso, quando dizemos institucionalização também pronunciamos o apelo às proibições ou concessões inerentes ao que está ordenado e instituído. A coerção, impondo-se formal ou informalmente, auxilia na definição da conduta do agente. Veblen atribuiu singular importância ao processo de institucionalização de comportamentos ou valores ao longo de sua obra. Teve a preocupação fundamental de explicar como as práticas sociais instituíam-se por meio dos imperativos materiais. Alguns exemplos recolhidos da sua argumentação permitem conjecturar que os atributos econômicos da vida diária têm especial relevância na institucionalização de hábitos coletivos. Segundo sua avaliação, são principalmente as "forças econômicas" as responsáveis pela manutenção ou pelo "reajustamento das instituições" na sociedade industrial contemporânea (VEBLEN, 1965a, p.184).

Para Veblen, o substrato material na definição institucional tem um caso histórico célebre: a classe ociosa. Segundo o autor, a instituição da classe ociosa seria uma das "primeiras consequências da propriedade” (VEBLEN, 1965a, p.51). Tal institucionalização processouse de modo tão mais cristalizado, ao longo do tempo, quanto maiores foram os desdobramentos da prática pecuniária, completa o autor. A 
ideia de propriedade também não teria uma aceitação quase irrestrita no ocidente se não tivesse alcançado uma dimensão institucional.

$\mathrm{O}$ investido direito de propriedade sobre todos os tipos de bens têm a sanção dos honrados princípios da escolha individual, da igualdade de oportunidades, do livre contrato, da segurança de ganhos e posses (VEBLEN, 1964b, p.22).

Muito embora a raiz da propriedade se encontrasse na aurora da humanidade, sua estabilização institucional deu-se muito depois. As decorrências desse processo, bem como seu acolhimento num universo jurídico, político ou moral, são frutos que somente puderam ser colhidos no contexto do século XVIII, sendo a tradição reformista (ou revolucionária) do Iluminismo a principal responsável por cimentar novos hábitos de pensamento a partir de hábitos de vida já consagrados (VEBLEN, 1964b, p.22-23). Tradicionalmente, argumenta Veblen, "hábitos institucionais de pensamento" garantiram e perpetuaram o "domínio da propriedade" (1932, p.68). Tratam-se, aqui, de hábitos de vida pecuniários produzindo hábitos de pensamento da mesma espécie, ou padrões regulares de conduta exploratória forjando a aceitação dos mecanismos de dominação.

Quando o autor aponta para a produção de hábitos de pensamento, quer ele reafirmar a criação das instituições. Este processo envolve-se de uma dinâmica própria e demanda a compreensão da mudança institucional, na forma como foi pensada por Veblen. Como leitor da obra de Charles Darwin, Veblen não ficou imune a considerável influência que o inglês produzira em seus contemporâneos. No início do oitavo capítulo de A Teoria da Classe Ociosa, vislumbramos uma inevitável confluência da ideia de dinâmica institucional e evolução darwinista.

A evolução da estrutura social foi um processo de seleção natural das instituições. O progresso que se fez e que se vai fazendo nas instituições humanas e no caráter humano, pode-se considerar, de um modo geral, uma seleção natural dos hábitos mentais mais aptos e um processo de adaptação forçada dos indivíduos a um ambiente que vem mudando progressivamente mediante o desenvolvimento da comunidade e a mudança das instituições sob as quais o homem vive (VEBLEN, 1965a, p.177). 
A dinâmica das instituições relaciona-se com o poder de adaptação e permanência das mesmas. É, em última instância, o "desenvolvimento da comunidade" que se impõe para a renovação institucional. De outro modo, a substituição de uma instituição por outra induz à adaptação dos indivíduos e, por conseguinte, da comunidade. Curioso, porém, é que Veblen dá à mudança institucional um status evolutivo, compondo-se mediante um "processo de seleção natural". A história, neste sentido, seria o desdobramento dessa evolução institucional.

As instituições são elas próprias o resultado de um processo seletivo e adaptativo que modela os tipos prevalecentes ou dominantes, de atitudes e aptidões espirituais; são, ao mesmo tempo, métodos especiais de vida e de relações humanas, e constituem, por sua vez, fatores eficientes de seleção. De modo que as instituições em mudança levam por seu turno a uma ulterior seleção de indivíduos dotados de temperamento mais apto e a uma ulterior adaptação do temperamento individual e seus hábitos ao ambiente mutável, mediante a formação de novas instituições (1965a, p.177-78).

A instituição modela-se pelas implicações das estruturas comportamentais renovadas pela própria instituição. Logo, a esclerose de determinadas instituições prepara o ambiente para a aceitação de novas normas ou padrões de conduta. Instituições sobrevivem e renovam-se desde que adaptadas às exigências da dimensão material das sociedades e suas produções sociais. As instituições "têm de mudar com a mudança das circunstâncias", contemporizando com as paulatinas ocorrências do universo cotidiano (VEBLEN, 1965a, p.179). São as circunstâncias que provocam mudanças institucionais, mas tais circunstâncias são elas próprias um elemento residual das instituições já consolidadas.

Nesse quadro Veblen opta por retirar do indivíduo o papel de plenipotenciário de suas ações na definição da instituição. Permite-nos entrever, novamente, o poder coercitivo dos padrões institucionais. Outrossim, revela-se o peso das condições herdadas institucionalmente, constrangendo o indivíduo e limitando o nível de liberdade do sujeito social.

A liberdade e a facilidade de reajustamento, isto é, a capacidade de desenvolvimento na estrutura social, dependem portanto, em grande 
extensão, do grau de liberdade mediante o qual a situação, em qualquer época determinada, atua nos membros individuais da comunidade, isto é, do grau de exposição dos membros individuais da coletividade às forças constrangedoras do ambiente (VEBLEN, 1965a, p.181).

As estruturas pretéritas são dotadas de um vigor não desprezível e, em consequência, sombreiam as atitudes presentes. Somente a renovação dos "hábitos mentais" implica na renovação institucional (1965a, p.180). Não, porém, a renovação dos hábitos de um ou outro segmento social, mas de toda a comunidade. Logo, na forma como foram pensadas pelo teórico social, as instituições têm antes uma vocação para conservar do que para mudar, antes se aliam à preservação de dadas estruturas do que a uma dinâmica social de rupturas contínuas. O reajustamento institucional é produto que se relaciona intrinsecamente à pressão exercida pelo ambiente social. Tal ambiente não se constitui ou não se avoluma, pondera Veblen, sem que haja um influxo de necessidades materiais, ou seja, a força persuasiva que modela a pressão ambiental está inevitavelmente associada às "exigências pecuniárias" (1965a, p.183). Nas necessidades materiais que compõem a força do ambiente social também encontramos os elementos tecnológicos, devidamente socializados no universo cotidiano do grupo social.

A forte presença da ideia de evolução não contaminou tão somente os textos veblenianos, senão boa parte da intelectualidade de sua época. Notadamente o Iluminismo, já no século XVIII, cooperou para a criação dessa atmosfera particular que perduraria pelo século XIX afora, até, talvez, o início do XX. Em Veblen o viés evolutivo pode ser apreciado como componente essencial na mudança institucional. A disposição cultural das sociedades ao longo da história, até a época industrial, refletiria a exata disposição institucional. Desse modo, esta "civilização material" também se apresenta como um "esquema de instituições - trama institucional e crescimento institucional” (VEBLEN, 1969, p.241).

O autor acredita que o próprio desenrolar da história da humanidade pode ser enquadrado num processo evolutivo e necessário, do qual decorrem instituições que refletem algo das relações sócioeconômicas de época. Não por acaso Veblen alude a pelo menos qua- 
tro instantes de desenvolvimento histórico. Apesar de não se dar ao trabalho de fixá-los no espaço e no tempo, é possível a partir de suas observações adequá-los genericamente em determinados períodos históricos, sendo o ocidente, sobretudo a Europa, a referência.

O primeiro deles foi identificado como de selvageria primitiva, termo associado à pré-história, economicamente fundada no seminomadismo, na agricultura ou no pastoreio. $O$ segundo marcou o advento da competição e do poder baseado no prestígio, momento denominado de barbarismo, cuja sociedade era controlada por uma classe ociosa. A passagem do primeiro para o segundo cenário histórico representou a "transição de um modo de vida pacífico para um mais consistentemente guerreiro", momento em que a "agressão se tornou a forma mais prestigiosa de ação" (VEBLEN, 1965a, p.24 e 32). Os sinais da transição do segundo para o terceiro cenário podem ser notados, segundo Veblen, pela superação de um estágio predatório, de economia desorganizada e vida social hostil, para um denominado de "quase-pacífico", ambos "fases sucessivas da vida bárbara” (1965a, p.71). A organização da vida econômica e um novo aparato institucional, no fim do barbarismo (na pequena fase "quase-pacífica"), lançaram as bases de uma economia artesanal, com referências a um mundo urbano e comercial identificado com o fim do medievo europeu, sendo este o terceiro momento histórico. O quarto e último deles foi identificado pelo autor como a "era da indústria", com a inovação tecnológica e as novas formas de organização dos processos administrativos e fabris, momento que se vincula à Revolução Industrial européia, fins do século XVIII em diante (VEBLEN, 1932, p.20-35) ${ }^{3}$.

De modo geral, sendo um homem de sua época, Veblen, como se vê, não conseguiu ficar imune a uma característica inerente do evolucionismo histórico do período: a ideia de evolução cultural unilinear. Quer dizer, implicitamente o autor parece partilhar da percepção de que no desenvolvimento histórico as sociedades

3 No que diz respeito aos supostos estágios de desenvolvimento humano, Veblen evidencia a influência, talvez difusa, que sofrera das ideias do etnógrafo norte-americano Lewis Henry Morgan (1818-1881), que consagrara as noções de selvageria, barbarismo e civilização. 
seriam conduzidas de um estágio primitivo para um civilizacional. A noção é de que os grupos sociais seguem uma mesma sequência de etapas. Como é aceito atualmente, tal percepção era clássica à sua época, mas notadamente equivocada para a antropologia do século XX, embasada numa perspectiva multilinear.

\section{A presença do evolucionismo}

Já dissemos aqui que para Veblen a dinâmica das instituições está diretamente relacionada à sua capacidade de adaptação e permanência na história. Na estrutura e no padrão de funcionamento das instituições, o autor advoga um caráter necessariamente evolutivo. Como consequência, esse viés evolutivo das instituições redunda numa interpretação também evolutiva da sociedade e da economia. A avaliação econômica que seguia esse caminho ficou conhecida como "economia evolucionária", sendo Veblen seu fundador e principal expoente.

A ambientação intelectual que permite essa perspectiva relaciona-se com dois momentos da história da ciência: primeiro, é a aceitação um tanto ampla do conceito de evolução em seu aspecto generalizante, próprio do século XIX; segundo, é a influência do trabalho de Charles Darwin. O primeiro momento diz respeito ao contexto típico daquele século, desdobrando a herança da tradição iluminista (DEGLER, 1991, p.5). O ponto de relevância, aqui, é a aprovação da natureza evolutiva do homem e da sociedade vinculada à noção de progresso geral da humanidade. Tais posições em muito se orientavam pela tradição intelectual oriunda dos séculos XVII e, sobretudo, XVIII, contexto típico das "afirmações entusiásticas de melhoria inevitável numa ou noutra faceta da vida humana” (BOCK, 1980, p.67). A incorporação total ou parcial dessa visão contaminou muito dos filósofos e cientistas sociais de então, contribuindo para disseminar utopias reformistas tão ao gosto daquele momento. Não demorou para que as teorias sociais dessa tradição, numa caracterização tipicamente prescritiva, passassem a atribuir como desejável o melhoramento do homem e da sociedade. Nessa mesma lógica outros tantos passaram a ver como absolutamente necessário o que era visto como desejável. 
É plausível aceitarmos que nestas teorias sociais a interpretação histórica do progresso humano não tenha deixado de suscitar implicitamente algum juízo de valor. Interpretações dessa natureza incorporavam como seu atributo essencial uma sucessão marcada não pela vitória de sociedades consideradas arcaicas ou supostamente estabelecidas sobre padrões culturais de menor envergadura, mas antes pela aceitação mais ou menos geral de formas de organização social tidas como superiores, lastreadas em crenças culturais também presumidas como tal. Nesse contexto, a naturalidade com que se aceitava certa evolução moral da humanidade através dos tempos redundou também na naturalização de discursos melhoristas, ou seja, imaginar uma inevitável sequência unilinear para os grupos humanos já trazia qualquer coisa de uma intervenção seletiva para aprimorar - entenda-se dominar - os que estavam em descompasso com o sucesso daqueles considerados mais avançados. Por esta razão é que a ideia de progresso, na sugestão de Bock, estava carregada de "conotações normativas", não sendo incomum a sua absorção pela teoria sociológica, sobretudo no século XIX (1980, p.67).

Herbert Spencer talvez tenha representado o posicionamento mais extremo desse legado. Voltando-se para uma dimensão social da ideia de evolução, sua filosofia permitiu-lhe concluir que o conflito e a sobrevivência têm um papel característico, funcionando como uma "espécie de processo biológico purificador" (MARTINDALE, 1968, p.191). A popularização de suas teorias levou os entusiastas a concluírem que à humanidade estaria assegurado o direito de resistir aos imperativos morais considerados arcaicos, responsáveis pela obstrução do processo evolutivo que, na concepção spenceriana, tinha a ver com melhoramento da espécie ${ }^{4}$. O conceito de evolução adquiriu status e foi incorporado ao pensamento da época, de modo que impregnou as "explicações supostamente científicas de desenvolvimento social até a Primeira Guerra Mundial” (HAWTHORN, 1982, p.101). As teorias spencerianas entraram para a história como a expressão mais definida do "darwinismo social". Conforme Degler, a evolução,

4 Sob inspiração de Spencer, justificativas não menos eloquentes, usadas para naturalizar o poderio econômico e o capital monopolista, podem ser creditadas a capitalistas do porte de um John D. Rockefeller ou de um Andrew Carnegie, como atesta Martindale (1968, p.192). 
na forma como aparecia nos trabalhos de Spencer, foi defendida pelo autor antes mesmo do aparecimento, em 1859, de A Origem das Espécies, de Darwin (1991, p.11). A ideia chave de "sobrevivência do mais adaptado", sintetizada por Spencer, passou a dar referência ao processo evolutivo mesmo dentro dos princípios darwinistas.

Se Spencer popularizou o termo evolução, que já estava difuso em certos círculos acadêmicos, Darwin foi o responsável por dar a densidade científica que o termo requeria. Aqui encontramos o segundo momento da história da ciência que auxiliou na ambientação dos argumentos evolucionistas. Em muitos sentidos a teoria de Darwin cristalizou a ideia de um processo evolutivo necessário para as espécies. Imerso no contexto intelectual de meados do século XIX, o naturalista já se via às voltas com os dilemas que envolviam o conceito de evolução. Nesse sentido, é preciso ressaltar que a tradição de pensamento evolucionista na teoria social consolidou-se com antecedência ao mesmo ponto de vista expresso na biologia do período (BOCK, 1980, p.105). Na composição de sua teoria, Darwin trazia elementos novos que redirecionaram a discussão acerca do desenvolvimento dos seres vivos, mas o esforço darwinista pode ser "compreendido como a culminância, antes do que a iniciação, de uma linha de pensamento que via a mudança evolutiva no homem e na natureza" (DEGLER, 1991, p.6).

É em meio a esse debate, a evolução pré e pós Darwin, que podemos compreender a ambientação intelectual que influencia os acadêmicos de fins do XIX e início do XX, dentre eles o próprio Veblen, cujas ideias de uma ciência pós-darwinista e de uma investigação econômica evolucionária somente podem ser avaliadas nesse contexto. Muitos dos cientistas sociais daquele momento sentiram de bom grado o discurso evolutivo que chegava, quer com Spencer quer com Darwin, para a sua aplicação no universo social. Porém, a absorção de argumentos oriundos da biologia resultou em avaliações incômodas do comportamento humano. Certa porção das ciências sociais, categorizadas pejorativamente na história, fazia uso da "sobrevivência do mais apto" como o mote que servia para justificar ideologias. Hawthorn associa Spencer e Darwin como componentes fundamentais dessa visão - voluntário no primeiro caso e involuntário no segundo. 
Importa-nos, sobretudo, salientar a relevância que a análise evolutiva teve no universo acadêmico norte-americano. Os princípios estabelecidos por Darwin seduziram demasiadamente as ciências sociais daquele país. A evolução vista sob o ângulo darwinista funcionou como um "catalisador do sonho" de "unificar as ciências sociais" e construir uma "teoria ampla que compreendesse os crescentes e diversos campos que fazem a celebrada e esperada "ciência do homem”' (DEGLER, 1991, p.314).

Veblen, à sua época, defendeu a importância do darwinismo como componente explicativo da mudança institucional; suas definições de ciência pré e pós-darwinista coroaram sua crítica metodológica da economia neoclássica. Nesse esquema, a teoria evolutiva estava, na ótica vebleniana, mais em consonância com o desenvolvimento das sociedades através da história do que com os imperativos da sobrevivência do indivíduo, compreendido como unidade econômica singular. A aposta do teórico não se baseou na competição e na sobrevivência do mais apto, tampouco resultou em premissas preconceituosas. Até por isso, talvez, seja aceitável que o autor não tenha sido enquadrado nos limites do darwinismo social, considerando-se a história e o desenrolar do pensamento sociológico. De todo modo, a importância da teoria evolutiva darwinista, para Veblen, é inequívoca. O impacto do darwinismo não só foi visto pelo autor como um novo momento das explicações científicas, como, para ele, tratava-se de difundir o seu eixo explicativo para outras disciplinas.

'Darwinismo' para Veblen marcou o começo de uma era, não somente porque ele simbolizou a revolução na biologia, mas porque foi destinado a fixar o tom de toda investigação intelectual subsequente. Ele usou o Darwinismo como um conveniente rótulo e interpretou toda uma série de implicações, fazendo isso claramente ele divorciou o Darwinismo de Darwin. Logo, incorporou um novo código de ciência, no qual cada investigação tinha que se conformar se quisesse ser aceita como 'científica' pela opinião moderna (MURPHREE, 1994, p.118).

O teórico não deu vazão à sua economia evolucionária balizado pelas singularidades de uma interpretação biológica da sociedade. Imerso no contexto de época, é verdade, não saiu ileso 
quanto à dispersão de um abrangente discurso evolutivo no ambiente intelectual em que vivia. Contudo, ao usar o discurso evolutivo na composição de suas conjecturas a respeito da mudança institucional, salientamos que ele não partiu de uma visão na qual o progresso fosse o elemento explicativo exclusivo, e nem chegou numa teoria preconceituosa ou excludente das sociedades humanas, algo não muito incomum à época. Sua proposta de uma economia evolucionária voltava-se, sobretudo, para a dinâmica institucional, destacando um viés multidisciplinar cuja contribuição central recaía sobre a história, a sociologia e a antropologia.

\section{Institucionalismo vebleniano}

Como já vimos, a compreensão vebleniana sobre as instituições permitiu ao autor configurar uma corrente interpretativa renovada para a economia de seu período, que ficou conhecida com o sugestivo nome de "economia evolucionária". Já ao longo do século XX, a interpretação das instituições, da qual Veblen foi um dos arquitetos, como que transbordou para as demais ciências sociais, talvez de modo um tanto enviesado, cunhando-se, então, a expressão "institucionalismo".

A noção de economia evolucionária confundiu-se com a de economia institucionalista ou por ela foi encampada, o que provavelmente fosse mais correto. A primeira estava associada especificamente a Veblen e seus seguidores, num esforço para manter a originalidade. A segunda, associada a uma tradição iniciada pelo autor, mas desdobrada em múltiplas interpretações que vêem o desenrolar das instituições como componente essencial para o estudo econômico. Aparentemente o termo institucionalismo adequava-se melhor para esse propósito, ademais o termo evolucionário implicava na aceitação, um tanto implícita, de elementos darwinistas, o que foi visto no decorrer do século XX como fora de moda ou pejorativo demais para o estudo das sociedades humanas. Blaug sugere que o institucionalismo ameaçou "tornar-se a corrente dominante do pensamento econômico americano" (1999, p.124).

Frise-se, porém, que as fronteiras do que se entende por institucionalismo nunca foram demarcadas com precisão. Olhando-o de 
modo um tanto genérico, o institucionalismo permite a inclusão de variantes interpretativas que defendem a relevância da história para o entendimento do presente ou a primazia de componentes herdados socialmente no estudo dos grupos humanos. A avaliação dos fenômenos sociais dar-se-ia numa perspectiva diacrônica, considerando a motivação como fator mais exógeno do que endógeno. A amplitude explicativa seria, portanto, própria dessa concepção de pesquisa.

Logo, a eloquência do institucionalismo econômico vebleniano, permanente nos seus herdeiros, reside numa cadeia argumentativa capaz de conjugar as instituições como componentes econômicos essenciais na definição da conduta dos indivíduos em sociedade. Inerente a essa explicação era o enfrentamento da mudança da "tecnologia e o desenvolvimento geral do conhecimento e das ideias", bem como a parcimoniosa transformação dos valores e das regras de conduta, forças centrais para a funcionalidade dos processos produtivos (HOMAN, 1971, p.536). A competitividade, os jogos de poder, a organização classista, a definição dos gostos, os desejos de consumo, a formação dos preços, a aceitação da moeda, e todos os demais requisitos de uma análise econômica bem sucedida, somente têm sentido se investigados num enquadramento histórico, se possível apresentando as relações de causalidade que os vinculam a episódios pretéritos.

É razoável aceitarmos que a indefinição dos limites do que se quer por institucionalismo acabou servindo como meio para depreciá-lo: afinal aquilo que vem para explicar tudo acaba nada explicando. Talvez por isso, poderíamos incluir na tradição da economia institucionalista uma dezena de autores que nada têm a ver com ela, a despeito de usarem da história como mecanismo privilegiado no entendimento das sociedades humanas ${ }^{5}$.

5 A dificuldade em se demarcar as fronteiras do institucionalismo permite conjecturas pouco ortodoxas, pois poderiam Marx ou Weber partilhar de tal tradição. Nesse rumo, Homan sublinha a preocupação de Marx com a "evolução das instituições econômicas", assim como aponta Weber como o "campeão da economia institucional na Alemanha" (1971: p. 535 e 538). Guardando paralelo com sua matriz mais distante, é significativo que também o neo-institucionalismo não constitua "uma corrente de pensamento unificada" (HALL \& TAYLOR, 2003, p.193). 
Curioso notar que, dada a ausência de um escopo metodológico definido no institucionalismo, haja autores que busquem confluência da perspectiva vebleniana com a teoria marxista. Diggins, a exemplo, vê convergência em ambos no que diz respeito à dominação de classe que, no caso do institucionalismo de Veblen, traz componentes culturais que se somam aos econômicos num grau muito maior do que pretendera Marx (1983, p.80-81). A alienação seria um mote comum aos dois clássicos, mas Diggins limita as comparações, haja vista que a teoria do valor marxista não coaduna com os propósitos de Veblen (1983, p.75-78).

Hunt, por sua vez, discutindo as similaridades e diferenças de ambos, projeta uma perspectiva complementar quando se trata da avaliação do capitalismo (1994, p.220). O marxismo contemporâneo teria em Veblen antes um aliado que auxiliaria na afinação do projeto crítico marxista - razão pela qual Hunt alude à simpatia de Veblen em relação ao socialismo, presente em algumas passagens de seus textos (1994, p.242).

Intérpretes da tradição institucionalista não deixaram de se esforçar para a demarcação do território, inclusive com novas conceituações. Dugger denomina, a exemplo, o institucionalismo vebleniano como "Institucionalismo Radical" - em parte para que não se confunda, ou se contamine, com o neo-institucionalismo bem mais recente (1994, p.552). Em seu artigo, Dugger defende que as críticas ao capitalismo na sua fase industrial e à sociedade daí decorrente, presentes em Veblen, definem a radicalismo de sua proposta, bem como o aproximam de Marx. Pelo menos sete pontos são listados pelo autor na definição desse institucionalismo: (1) a natureza processual da economia, para além do equilíbrio neoclássico; (2) a averiguação da irracionalidade que permeia as classes exploradas; (3) a denúncia da dominação baseada no status, no poder, no mito; (4) a defesa da igualdade; (5) o propósito pragmático aliado à sustentação filosófica - "fusão do instrumentalismo e do existencialismo", conforme o autor; (6) democracia; e (7) transformação radical da sociedade (DUGGER, 1994b, p.552-571).

Suspeitamos de pelo menos dois pontos apresentados por Dugger. O item quatro e o sete são complementares, pois a transformação radical da sociedade redunda na aproximação da ideia de 
igualdade. Para além da igualdade política e jurídica, os princípios do igualitarismo social, demasiadamente sedutores na atmosfera da $2^{\underline{a}}$ Revolução Industrial, não foram defendidos de modo promissor na obra de Veblen. Nesse sentido, a argumentação hesitante e pouco definida sobre o papel dos técnicos, cientistas e engenheiros, levada adiante em alguns momentos do autor, sobretudo em The Engineers and the Price System, menos coincide com a transformação radical da sociedade do que com a crítica ao instinto predatório dos capitalistas em meio à especulação no mercado de ações.

Davis sugere, sobre a teoria vebleniana, certa harmonia e um "parentesco espiritual" com o marxismo, considerando a oposição agudamente crítica de ambos às situações de poder provenientes da sociedade industrial. Sem muita elaboração, o autor aponta que as decorrências dessas situações de poder são as clivagens de classe, no que diz respeito às suas posições e interesses, e à noção de evolução cultural através da história (DAVIS, 1994, p. 30 e 43).

De maneira geral, há uma condescendência dos marxistas em relação a Veblen e sua teoria, a qual supomos se basear em pelo menos três fatores essenciais. Em primeiro lugar, a personalidade conflitante do pensador, uma espécie de outsider acadêmico, aproximava-se da contestação a tudo o que era formalmente instituído, o que garantiu simpatizantes afeitos à rebeldia social. Em segundo, os textos veblenianos, numa visão mais simplista, fazem a denúncia do capitalismo e da estrutura de valores dele decorrente. Em terceiro, sua economia evolucionária converge com a marxista na tentativa de solapar as bases fundamentadoras da economia neoclássica, singularizando a história no universo explicativo.

Este último fator sintoniza-se com a explicação de Spengler e Allen, demonstrando que as tradições econômicas clássica e neoclássica estiveram à mercê de três grandes correntes teóricas, de fins do XIX em diante: a marxista, dominante sobre todas as posições socialistas; os diversos autores e escolas de pensamento que privilegiavam um enfoque histórico na conduta econômica, das quais o historicismo alemão foi a mais eminente; e os estudos institucionalistas que partiram de Veblen e de seus seguidores (1971, p.497). Na economia, particularmente, o institucionalismo teve como propósito atacar a tradição econômica neoclássica. Por este 
motivo os institucionalistas afirmavam que o estudo econômico só era válido se abarcasse a totalidade dos componentes da dinâmica social. A apreensão dessa totalidade dar-se-ia através das instituições, entendidas, como vimos, não apenas no universo formal, como organizações constituídas, mas, sobretudo, como elementos imateriais do comportamento humano, num universo cultural.

Assim, a economia institucional parte da dinâmica das sociedades e não estritamente de seus eventos particulares. As relações sociais adquirem um novo status e os indivíduos deixam de ser vistos como fatores de motivação econômica exclusivos. A ideia de maximização de resultados particulares, tão solenemente centralizada na economia clássica e neoclássica, torna-se coadjuvante frente às novas preocupações do institucionalismo.

Veblen procurou diminuir o peso da tradição do laissez-faire anglo-saxônico, típico entre os economistas da ocasião, pois nela estavam embutidos o individualismo e a noção da vontade pessoal como marca distintiva da realização. Em sua projeção teórica, Veblen pensava no peso das formas instituídas de relacionar-se socialmente, do mesmo modo que se opunha ao marginalismo neoclássico. Assim, apesar de conjugar, em algum grau, os atributos da racionalidade humana na ação social, essencialmente apostou em forças exógenas, como as instituições e a história, na definição da dinâmica das relações sociais.

Sua interpretação ancorava-se na noção de que as instituições sociais, como hábitos de pensamento coletivos, acomodavam-se num processo evolutivo ao longo da história, respaldando aquelas bem sucedidas - ou bem adaptadas - em detrimento daquelas incapazes de responder às necessidades do grupo. Muito embora Veblen não aceitasse os discursos viciados pelo determinismo, dado seu encantamento com as noções de causalidade de uma ciência pós-darwinista sem fins presumidos, o conjunto de seus textos não deixou de impregnar-se por certo vício teleológico. Afinal, tal qual os darwinistas sociais de seu tempo, sua compreensão do processo histórico permitiu a incorporação de etapas civilizacionais enquadrando o desenvolvimento humano, com distintas fases de gradativa mudança institucional, como a selvageria primitiva, o barbarismo, a era artesanal ou a industrial. 
Para Veblen, o grande dilema era apegar-se a uma interpretação conservadora da história e, ao mesmo tempo, tentar construir uma adequada crítica das situações de poder, do passado e do presente, sem que isso implicasse em qualquer forma de determinismo. Por isso, alinhou-se, em algum grau, ao indutivismo, mesmo estando sob a tutela de uma época em que não era de todo estranho, nas ciências sociais, tomar a frágil noção de que leis naturais podiam reger o comportamento social. Logo, o autor viu-se na curiosa situação de desvencilhar-se criticamente de seu contexto de época, ainda que cativo do emaranhado das influências que o formaram.

Veblen estava preso a um ambiente sufocado com os elementos do darwinismo social, atmosfera que não permitia que muitos intelectuais do período escapassem das noções depurativas da sociedade. A teoria de Darwin, por sua vez, sombreou muito desses equívocos justificadores de certa ordem natural - menos como desdobramento teórico inevitável e mais como acomodação de princípios explicativos coerentes para a dominação social. Assim, a contragosto, o darwinismo redundou, em fins do XIX, na explicação aparentemente mais confiável para o entendimento e ajustamento das situações sócio-econômicas adversas nas quais a humanidade encontrava-se, por conta, em parte, da segunda Revolução Industrial. O convívio social economicamente hostil, entre os membros da sociedade, foi corriqueiramente naturalizado como fenômeno intrínseco da espécie.

Veblen viveu nesse contexto e dele procurou escapar. Em grande medida, sua obra refletiu um esforço na utilização dos princípios darwinistas, sem, contudo, deixar-se contaminar pelo spencerianismo difuso em seu tempo. A exemplo, a concepção vebleniana de instinto denotou a energia gasta pelo autor para fugir dos imperativos biológicos que quase arrastam por gravidade o termo. De resto, tal concepção permitiu aprumar os condicionantes sociais como atributos básicos para a ação, viabilizando uma metodologia de natureza holista.

O holismo, presente na teoria vebleniana, alimentou-se da ideia de mudança institucional cumulativa e do conceito de hábito institucionalizado, ambos convergindo para superar o individualismo racional dos neoclássicos e seus subprodutos, como a ma- 
ximização de resultados, a motivação hedonista e o princípio de equilíbrio mercadológico. Como sublinhamos, Veblen alargou sua compreensão holista da dinâmica social incorporando o conceito de instinto, que, não se reduzindo ao universo da biologia, procurava alcançar um potencial explicativo mais plural.

A despeito da importância dos instintos paternal e da curiosidade ociosa, foram os da produção e predatório que frequentaram, de modo mais constante, os argumentos do autor. A dualidade antinômica, por eles representada, implicava na aceitação de forças motrizes socialmente instaladas desde remotos tempos. $O$ primeiro destinado a promover a cooperação e a existência material da vida em comunidade; o segundo responsável por manter e reproduzir uma estrutura de poder e status, da qual a classe ociosa, os capitães das finanças ou os proprietários ausentes se serviam.

A economia neoclássica, ao naturalizar as situações de competição e mercado, na sugestão de Veblen, fundamentava as práticas do instinto predatório mais que as do instinto produtivo. Bem sabemos que o autor, em posição oposta, ao criticar a predação, fez emergir a ideia de um instinto da produção como caminho necessário para a superação das formas opressivas de relacionamento social. A teoria vebleniana, nesse sentido, talvez padecendo de alguma inspiração tardia do Iluminismo, não deixou de sublimar a ideia de cooperação social, sugerindo, implicitamente, que qualquer coisa de um comportamento natural pudesse ser reencontrado pela humanidade - como quem ainda se seduzia pelo "bom selvagem" tão típico de outros tempos.

O produto final da contribuição de Veblen equacionou componentes razoavelmente significativos para o estabelecimento de uma teoria social com alguma pretensão de ordem. Entre tais elementos agruparam-se o reformismo norte-americano, o darwinismo, a economia neoclássica, o historicismo, entre outros. Em vista dos debates ou da inspiração dos discursos de época, o resultado expresso pela teoria vebleniana dizia respeito a um novo modelo de investigação, sugerindo um caminho alternativo para o pensamento econômico majoritário, num país que já se adiantava em assumir a nova posição que lhe cabia no plano internacional. Logo, em Veblen, esboçou-se uma ruptura com a metodologia dominante na disciplina 
econômica da ocasião. Ruptura metodológica que, originando-se do arsenal sociológico ou da investigação histórica, para além da cristalização restrita das disciplinas, teve como destino o fortalecimento de uma interpretação tipicamente multidisciplinar, mais afeita aos termos clássicos das ciências sociais.

Recebido em: 2.2.2010 Aprovado em: 23.7.2010

\section{Referências}

BLAUG, M. Metodologia da Economia. Tradução: Afonso L. M. S. Lima. São Paulo: EDUSP. 1999.

BOCK, K. Teorias do progresso, desenvolvimento e evolução. In: BOTTOMORE, T. \& NISBET, R. História da Análise Sociológica. Tradução: Waltensir Dutra. Rio de Janeiro: Zahar Editores. 1980.

DAVIS, A.K. Sociological elements in Veblen's economic theory. In: WOOD, J.C. (Ed.). Thorstein Veblen: critical assessments (volume II). New York: Routledge. 1994.

DEGLER, C.N. In Search of Human Nature: the decline and revival of darwinism in american social thought. New York: Oxford University Press. 1991.

DIGGINS, J.P. El Bardo del Salvajismo: Thorstein Veblen y la teoria social moderna. Cidade do México: Fondo de Cultura Económica. 1983.

DUGGER, W.M. Radical Institutionalism: basic concepts. In: WOOD, John Cunningham (ed.). Thorstein Veblen: critical assessments (volume II). New York: Routledge. 1994.

HALL, P.A. \& TAYLOR, R.C.R. As três versões do neo-institucionalismo. In: Revista Lua Nova. São Paulo, n 58. 2003.

HAWTHORN, G. Iluminismo e Desespero. Rio de Janeiro: Paz e Terra. 1982.

HODGSON, G. M. Economics and Institutions: a manifesto for a Modern Institutional Economics. Philadelphia: University of Pennsylvania Press. 1988. 
HOMAN, P. T. La escuela institucional. In: SPENGLER, J.J. \& ALLEN, W.R. (Org.). El Pensamiento Econômico de Aristóteles a Marshall. Madri: Editorial Tecnos. 1971.

HUNT, E. K. The importance of Thorstein Veblen for contemporary marxism. In: WOOD, J. C. (Ed.). Thorstein Veblen: critical assessments (volume II). New York: Routledge. 1994.

LALLEMENT, M. Raízes alemãs da sociologia econômica. Tradução: Leonardo Mello e Silva. In: Tempo Social - Revista de Sociologia da USP. São Paulo, volume 18, n 1, junho. 2006.

MARTINDALE, D. La Teoria Sociologica: naturaleza y escuelas. Madri: Aguilar. 1968.

MURPHREE, I. Darwinism in Thorstein Veblen's Economics. In: WOOD, J.C. (Ed.). Thorstein Veblen: critical assessments (volume I). New York: Routledge. 1994.

ROSS, D. The Origins of American Social Science. Cambridge: Cambridge Univ. Press. 1997.

SILVA, V.L. A arqueologia da sociologia econômica: a contribuição de Thorstein Veblen. In: Estudos de Sociologia (Unesp). Araraquara/ SP, volume $13, \mathrm{n}^{\circ} 25,2^{\circ}$ semestre. 2008.

SPENGLER, J.J. \& ALLEN, W.R. El Pensamiento Econômico de Aristóteles a Marshall. Madri: Editorial Tecnos. 1971.

VEBLEN, T.B. The Theory of Business Enterprise (1 a edição: 1904). New York: Charles Scribner's Sons. 1932.

. Essays in our Changing Order (1’a edição: 1934). New York: A. Kelley. 1964a.

. The Vested Interests and the Common Man: the modern point of view and the new order (1 1 edição: 1919; publicado originalmente sob o título The Vested Interests and the State of the Industrial Arts). New York: A. M. Kelley. 1964b.

- A Teoria da Classe Ociosa: um estudo econômico das instituições. (1a edição em inglês: 1899). Tradução: Olívia Krähenbühl. São Paulo: Livraria Pioneira Editora. 1965a.

. The Engineers and the Price System (1ª edição: 1921). New York: A. M. Kelley. 1965b. 
. Veblen on Marx, Race, Science and Economics. The Place of Science in Modern Civilization and Other Essays (1 ${ }^{\mathrm{a}}$ edição: 1919). New York: Capricorn Books. 1969.

. The Instinct of Workmanship and the State of Industrial Arts (1ª edição: 1914). New Brunswick: Transaction Publishers. 1989.

WALLER, JR., W.T. The concept of habit in economic analysis. In: HODGSON, G. M. (Org.). The Economics of Institutions. Aldershot: E. Elgar Publishing. 1993.

\begin{abstract}
Fundaments of institutionalism in Thorstein Veblen's social theory

The text highlights the central terms present in the work of the American economist-sociologist Thorstein Veblen (1857-1929), pointing to the scope and limits of his explanatory concepts. We look at terms such as instinct, habits of life and thought which support his argument and enable us to get a clearer picture of his theoretical effort to build a model of analysis for understanding the social and economic dynamics of the Second Industrial Revolution, also meant to counter the neoclassical economics of his time. The salient feature of his work is its multidisciplinary character - typical of the social sciences- which has served as the basis for an approach that came to be known as Veblenian institutionalism.
\end{abstract}

Keywords: institutionalism, instinct, habits, institution. 
